\title{
Las encrucijadas de un modelo social
}

\section{M arlene Azor H ernández}

U niversidad de La H abana. Facultad de Filosofía e H istoria

La H abana. Cuba

\section{Sumario}

D escripción y análisis del modelo.

El sistema político

El subsistema económico

La ideología

La movilidad social

Existe una cuantiosa literatura sobre el colapso del modelo soviético que se expendió a las experiencias históricas de los socialismos de Estado en estos finales de siglo. Sin embargo, pocos autores ${ }^{1}$ han reflexionado sobre la totalidad del modelo al incorporar la economía, la estructura social, el sistema político y el funcionamiento de la ideología.

Junto con la experiencia fracasada, se descal ifica o se olvida la reflexión de miles de intel ectuales que desde 0 ccidente 0 dentro de los países del «socialismo real » evaluaron esas sociedades y han legado un acumulado de reflexión teórica val iosa. M e refiero en este caso a los investigadores que, colocados ante el desafío de conocer los procesos que ocurrían en el «socialismo real», no traspolaron los esquemas de funcionamiento de 0 ccidente para desautorizar lo que ocurría en el Este europeo, sino que intentaron evaluar esas sociedades desde los propios códigos políticos económicos y teóricos dominantes en esos procesos históricos.

Considero esa postura investigativa como la más profunda y fértil para comprender no sólo lo ocurrido, sino también aquello que es necesario mantener en la memoria histórica, resultado de un aprendizaje del pasado.

Lamentaba un economista chileno ${ }^{2}$ en 1982, que cada nuevo proceso de transición «socialista» discutía problemas comunes a otras experiencias similares como si se tratase de problemas inéditos. Paradójicamente, quienes más

1. Entre los que se encuentran BARH O, Rudolf (1977). La alternativa: por un comunismo democrático; T ROTSKY, León D. (1937). La revolución traicionada.

2. Vuskovic, Pedro. Revista de Economía, núm. 159-160, enero-junio de 1982. M éxico: UNAM . 
necesitaban conocer la experiencia acumulada para no repetir políticas erráticas, menos accedieron a esa información.

En la práctica, las experiencias históricas de transición «social ista» se desarrollaron con un doble síndrome defensivo. (La palabra síndrome denota que si bien la autora reconoce las condiciones real es que propiciaron esa postura, ella fue llevada sistemáticamente a extremos innecesarios.)

$\mathrm{H}$ acia el interior de esos países la vertiginosa modernización exigió altos niveles de control y organización social. Sin embargo, hacia el exterior se exportó una imagen idealizada con una posición defensiva propia de una «fortaleza sitiada».

Las direcciones sociales de estos procesos han sido extraordinariamente vulnerables a cualquier crítica, precisamente por asumirse responsables y gestores de toda la actividad social. No hubo ámbito de la sociedad en la cual no se elaboraran políticas y se controlara su ejecución. Esta centralización extrema ha sido motivo a la vez de fuerza y debilidad del régimen social. Fuerza por la posibilidad de movilización social de manera rápida y sistemática, debilidad por impedir la evaluación y reflexión sobre las políticas desarrolladas antes y después de cada cambio.

Políticas que debieron ser canceladas rápidamente o nunca puestas en marcha, se mantuvieron durante décadas por esa falta de retroalimentación social. No se trata sólo de la evaluación de los expertos, nos referimos al estudio del impacto de esas políticas en la sociedad civil.

Las experiencias históricas de los socialismos de Estado han bloqueado sistemáticamente una reflexión continua sobre los problemas que surgían con las grandes transformaciones modernizadoras que se producían en sus sociedades, y la censura se trasladó también a los partidos comunistas occidentales y a la izquierda en general. Así se explica el distanciamiento de los marxistas occidentales de los problemas de las experiencias del «socialismo real», para evitar una fractura con sus partidos o una ruptura con sus filiaciones de izquierda. El panorama cambió a finales de los años sesenta e inicios de los años setenta.

No obstante, al interior del «socialismo real» el debate se mantuvo estrictamente acotado, cuando no definitivamente ausente 3 . Corolario de lo anterior es la poca fiabilidad de las estadísticas oficiales de esos procesos o la ausencia durante períodos relativamente largos de estadísticas económicas o de otro tipo que permitieran hacer investigaciones sociales serias.

Convertir en «secreto de Estado» desde el costo y el surtido de la canasta básica familiar, el resultado de una política fallida o la estructura ocupacional y de ingresos - por mencionar algunos ejemplos- actuaron en detrimento de los estudios social es rigurosos y evitaron además la posibilidad de que las

3. La polémica más completa y abierta que se haya dado dentro del «socialismo real» es la ocurrida en los años veinte en la ex-U RSS, y ella tuvo la impronta de las metas privilegiadas por la dirección bolchevique. También el debate de los años sesenta en Checoslovaquia intentó realizar una reforma profunda con signo diferente, pero fue interrumpida por la invasión soviética. 
políticas fueran elaboradas con toda la información necesaria y cumplieran su propósito de planificación a largo plazo, superioridad discutible después de analizar retrospectivamente estos procesos y constatar el grado de improvisación, espontaneidad y voluntarismos que reglan las decisiones sobre las políticas macrosociales.

Algún lector podría ripostar que, en efecto, estos procesos históricos han sido el resultado de actos de voluntad, pues según las condiciones que proponía M arx, las real idades de esos países no conducían a la transición "social ista». Se verificó entonces que el voluntarismo convertido en norma de actuación de la dirección social, desdeñando las señales de la realidad social, ha sido una de las causas de la autodestrucción de esos procesos. La evolución histórica demostró que en un momento de su desarrollo, estos regímenes fueron incapaces de continuar su autorreproducción y de asimilar cambios de envergadura manteniendo el mismo referente de su proyecto social, y eso se debió a factores estructurales internos aún cuando los desafíos llegasen a través de la influencia del ámbito internacional.

El presente artículo analiza los mecanismos internos de articulación social del modelo que ha dominado en los socialismos de Estado y que se elevaron como obstáculos infranqueables a su reproducción.

El modelo se construye a partir de una experiencia histórica y se trata de la generalización de los rasgos regulares o comunes a todas las experiencias de transición «socialista» en este siglo.

La división analítica en subsistemas responde a los fines de la explicación, pero se observa la interdependencia funcional entre ellos.

\section{Descripción y análisis del modelo. El subsistema económico}

Para describir este subsistema, me apoyo en el análisis de C atherine Samary sobre el modelo soviético, que ella designa con el nombre de «planificación burocráticamente centralizada». Todo el «socialismo real» aplicó este tipo de organización a la economía y salvo en la década de los años sesenta e inicios de los setenta con las reformas en Europa oriental - países como Polonia, Checoslovaquia, H ungría y Yugoslavia - descentralizaron el modelo para luego recentralizar sus economías. Cuba copió el modelo desde la década de los años setenta. C hina tiene sus peculiaridades en la aplicación del modelo, pero salvo el período del «gran salto» (1958-1961), el resto del tiempo hasta el avance de la reforma de 1978, basó la organización económica en similares preceptos.

Los rasgos más observables del sistema son4:

a) La tendencia a largo plazo a la disminución de la tasa de crecimiento de la renta nacional y la productividad, acompañada de un incremento de los costos.

4. SAm ARY, Catherine (1989). «Planificación, mercado y democracia. La experiencia de los Ilamados países socialistas». Cuadernos de Estudio e Investigación, núm. 7-8, 14-23. Francia. 
b) El crecimiento extensivo que combina el despilfarro con la escasez y una baja productividad del trabajo.

c) La escasez y los «cuellos de botella» en la producción, resultado de una pla nificación al detalle que no logra obtener la información adecuada sobre la oferta y la demanda de los factores productivos.

d) Una combinación de escasez de fuerza de trabajo y sobreempleo. En algunas ramas y ocupaciones se observa la fal ta de fuerza de trabajo, en otras no se aprovecha la jornada laboral por exceso de fuerza laboral. N o hay una proporción adecuada entre las tareas necesarias y el número de personas imprescindibles para cumplirlas.

e) La evaluación de los recursos existentes, la identificación de las necesida des y el control de los resultados de la producción, se realiza por burócratas a los distintos niveles. No existe contrapartida social sobre esta gestión.

f) La imposibilidad del control al detalle, en una economía diversificada y compleja, hace que la planificación sea en términos general es y difusos (en especie) 5 .

g) Los objetivos del plan están subordinados, en primer lugar, a factores extraeconómicos, en función de la estabilidad política y de la coyuntura internacional.

h) La planificación al detalle implica una relación empresa-centro y la imposibilidad de una relación económica entre las empresas en un sentido horizontal. Los insumos no adquiridos mediante la asignación del plan no son posibles de adquirir en relaciones de compra-venta legal con otras empresas, sino mediante canales «clandestinos»,

i) Los precios son designados desde el centro planificador. Éstos, desconectados de los precios internacionales, son de carácter histórico y su fundamentación es sociopolítica, no económica.

Estos factores son de tipo estructural, porque condicionan el tipo de agencia económica de productores y dirigentes de la producción y las relaciones entre ellos.

La manera de estructurar el sistema económico condiciona los siguientes rasgos en las relaciones de producción.

Los dirigentes del proceso productivo desde el nivel de la empresa hasta el centro en una escala piramidal de funcionarios son designados desde el centro, sean especialistas calificados en la rama o no. El criterio de selección es de índole política y no especialmente de mérito ${ }^{6}$, porque la eficiencia no se mide por la reducción de los costos, o por la iniciativa para aprovechar al máximo los recursos según términos racional es o por la introducción de nueva tecnología,

5. Al inicio de la década de los años ochenta, un semanario humorístico soviético Krokodil publicaba caricaturas que ejemplificaban el problema. Por ejemplo, aparecía un camión de carga con un único lápiz gigantesco. Al pie de la caricatura el texto «La industria del lápiz cumple su plan de producción».

6. M érito entendido sociológicamente como las capacidades especial es por un conocimiento científico-técnico específico. 
sino por el cumplimiento del plan o su sobrecumplimiento en términos difusos que esconden despilfarro e ineficiencia.

Los intereses de los burócratas se orientarán en función de conservar sus puestos y ascender en la escala burocrática.

Para ello deben cumplir el plan asignado y evitar conflictos y tensiones en las ramas que dirigen. El puesto brinda una serie de prebendas no asociadas al salario, sino a prerrogativas económicas y sociales extras (centros de compra especiales, de recreación y de atención médica). M ientras más se asciende en la «nomenclatura» más amplios son estos privilegios materiales escasos y de mejor calidad.

De lo anterior se desprende que los criterios de una «buena» gestión económica no se mide en términos de eficiencia racional de recursos, sino en una específica «eficiencia» que privilegia cumplir el plan, aunque sus resultados desencadenen una ineficiencia global. Es decir, la calidad del producto no determina su realización final en el mercado. Los consumidores (me refiero dentro del sistema productivo y no a los consumidores de bienes y servicios personales) están obligados a recibir y continuar el proceso productivo con bienes defectuosos que implican despilfarro en cuanto a durabilidad y eficacia del producto final. Estos problemas no detienen el cumplimiento del plan, porque no se exigen, o no tienen contrapartida para descalificarlo, ni entre los productores, ni entre los consumidores. No hay selección, porque no hay competencia, y siempre existe escasez. Con los bienes y servicios de consumo personal ocurre de igual manera. No hay posibilidades de consumo alternativo, porque todo es producido en las empresas estatales sumergidas en la lógica que hemos apuntado.

Como la demanda de los factores de producción sólo pueden ser desde las empresas hacia el centro, no existen canales alternativos de compra, los burócratas en el momento de evaluar los recursos necesarios para cumplir el plan, pedirán más recursos de los «históricamente» necesarios u ocultarán las disponibilidades que tienen de ciclos productivos anteriores, acumulando un stock de insumos inertes y depreciándose.

En la evaluación del monto de producción, se justifica por los burócratas un objetivo bajo, pues un objetivo alto de producción puede ser azaroso para cumplirlo.

En el momento de realización del plan, se controla de igual forma superficial y formal, según los índices que se piden desde el centro. Samary señala «... ] adicionalmente, tejer redes estables - de suministros por vías «clandestinas»- , presentar planes cuya realización se domina [... ] estas son [... ] las condiciones para triunfar» 7 . N 0 se trata de un enjuiciamiento ético de los burócratas, ni de la evaluación de su competencia profesional. El sistema de organización y control desde un centro, en una economía compleja exige y condiciona una conducta de este tipo. Por otra parte, los índices de producción «difusos» 0 en especie se debe a que la única manera de controlar una 
economía compleja con una centralización burocrática rígida es colocando índices que puedan ser homogéneos, comunes y de ahí su grado de generalidad.

Eliman 8 , al igual que numerosos autores, expresa la imposibilidad de obtener una información fidedigna en un sistema de este tipo. Las condiciones productivas tienen variables que pueden diferir de un día a otro, y varían de un tipo de actividad a otro, por sus dimensiones, equipamiento técnico, especialidad de productos, dependencia de otras ramas económicas, etc.

Como en todo el sistema económico, el control es formalizado en esos índices, cada burócrata en los distintos niveles oculta información o la distorsiona, para cumplir aquello que se le exige y mantener su estatus.

El chiste de la producción de carne de cerdo, es el ocuente para ejemplificar el problema y sus consecuencias:

Un dirigente nacional visita una empresa criadora de cerdos y el director le informa que las cerdas paridoras lograrán parir diez cerditos per cápita. Al finalizar el año, las cerdas sólo parieron la mitad, pero el director de la empresa no se arriesga a informar cinco, sino seis per cápita, el nivel inmediato superior tampoco se arriesga e informa siete. Así sucesivamente, y a nivel nacional llega la información de diez cerdos per cápita. El plan se «cumplió». Entonces, el centro planificador decide la distribución: $50 \%$ de la producción para la exportación y el resto para consumo interno.

Como se observa, hay una racionalidad no instrumental en la conducta de los burócratas. D e acuerdo a los fines reales que coloca como posibles el sistema económico, los funcionarios orientan los suyos y extraen los medios racionales menos costosos desde el punto de vista personal, para mantener su estatus, del modo en que le permite el sistema. U na conducta motivada a otros fines choca permanentemente con el sistema y es también de modo permanente desestimulada por los conflictos y riesgos personales que entraña, desde riesgos de tipo político porque la burocratización del sistema, la cristalización del poder en cada instancia posibilita procesos de acoso o difamación encubiertos en razones políticas, únicas válidas para separar de su puesto a burócratas o trabajadores, o riesgos de tipo médico, por las tensiones que genera intentar hacer eficiente un eslabón económico cuando el problema es de índole estructural.

Samary destaca: «[... ] todo intento constructivo de luchar contra el despilfarro y la incompetencia vía los pasillos de la jerarquía establecida han conducido, en el mejor de los casos, a un callejón sin salida y en el peor, a un hospital psiquiátrico»?.

$\mathrm{H}$ emos llegado al eje central del problema. El sistema económico en las experiencias históricas de socialismos de Estado han perseguido la finalidad del desarrollo, del crecimiento económico sostenido. Los mecanismos de orga-

8. ElLm AN, M ichael (1983). La planificación socialista. M éxico: Fondo de Cultura Económica, p. 86-96.

9. SAMARY, Catherine. 0 p. cit., p. 20. 
nización y control para estos fines, resultan medios antagónicos a medio y largo plazo. En los primeros momentos la efervescencia revolucionaria, o la militarización del sistema económico (en tiempos de Stalin), o la represión en la época del «G ran Salto» y luego en la «Revolución Cultural» en C hina, impiden que los medios antagónicos conduzcan a la desintegración del sistema, pero en la medida en que cristalizan estas estructuras en el tiempo el antagonismo entre medios y fines, exigirá reestructurar todo el sistema.

Esta reestructuración no será posible sólo con cierta descentralización de las estructuras, sino por la expansión del mercado, de la propiedad privada y del capital. Coincido con Samary en esa conclusión y paso a explicarla con mayor detalle.

Los intentos de descentralizar al gunos mecanismos de decisión y control económico en los países de Europa oriental condujeron a varios tipos de conflictos ${ }^{10}$ :

- Entre la capa burocrática «tradicional» y los tecnócratas que exigía un sistema descentralizado de gestión económica.

- Entre las industrias de alta demanda para el consumo popular y que resultaban rápidamente rentables, y las industrias extractivas o de medios de producción con subsidio estatal y bajos precios y salarios.

- Entre las zonas más desarrolladas, que debían pagar impuestos de mayor cuantía - teniendo mayor eficiencia - para subsidiar el desarrollo de las más atrasadas.

- Entre la exigencia de eficiencia y la imposibilidad de eliminar el sobreempleo.

- En el caso yugoslavo, durante el período de 1965-1971 que se experimentó el socialismo de mercado, el desempleo masivo obligó a emigraciones masivas de la fuerza de trabajo.

La diferenciación social en busca de la eficiencia económica, tuvo una resistencia creciente para sociedades que habían generado una conciencia social de igualitarismo y una disciplina laboral prácticamente formal y débil.

Precisamente la contrapartida de la conducta burocrática es permitir la relajación de la disciplina laboral, única resistencia de los trabajadores en el modelo de socialismo de Estado. La estructura del sistema condiciona tal resistencia.

D espués de los primeros tiempos, producir cada vez menos se convierte en la norma que guía la conducta de los trabajadores. Para el pensamiento marxista, esto se debe a que los trabajadores viven relaciones enaj enadas con respecto al control de la producción y de los resultados del trabajo. Sin embargo, una sociedad moderna de diferenciación y especialización creciente, no permitiría este tipo de control no especializado. Es contradictorio. $M$ andel se refiere a la posibilidad de un control no técnico, en aquellos aspectos de la producción 
no relacionados con la necesaria autoridad científico-técnica. En primer lugar, el modelo que anal izamos, por sus propios fines, y los medios que utiliza impide la posibilidad de este control. En segundo lugar, porque M andel apuesta a una conciencia política en los trabajadores que trascienda sus intereses personales. Esto puede ocurrir por breve tiempo o de manera puntual, pero es impensable una postura trascendentalista de este tipo como conducta masiva y cotidianall, a menos que se utilicen formas extremas de coacción (la militarización o represión que hemos comentado).

Existen razones que desestimulan el esfuerzo por un rendimiento mayor. El rendimiento creciente no tiene correlato en el ingreso. Las categorías de salarios son fijas y persiguen un mínimo de diferenciación social (incluso con la variante de los premios). En segundo lugar, un mayor rendimiento no conduce a escalar a un estatus superior. El límite en los ingresos y la reducida oferta de bienes y servicios (reducida con respecto a la demanda solvente), actúa a favor de un esfuerzo cada vez menor.

El principio marxista de distribución con arreglo al trabajo, es sistemáticamente devaluado en la práctica de los trabajadores. $\mathrm{H}$ ay un límite en las posibilidades de ingreso, un límite aún mayor en el consumo, y un límite en la movilidad social. Se impone una ética social de conformidad y ascetismo contraria a los valores que se pretenden difundir en los procesos de socialización.

H emos visto que las normas y valores que se estandarizan en el sistema económico son antagónicos con el desarrollo y el crecimiento sostenido. El sistema crea así una contradicción insal vable que atenta contra su supervivencia.

El estancamiento económico o su regresión, el retraso en la innovación tecnológica, la baja productividad del trabajo, o la perpetuación de un desarroIlo extensivo, cada vez más costoso, son epifenómenos de problemas estructurales profundos. Para eliminar esta lógica de funcionamiento, es necesario un cambio estructural tan radical como al inicio de estas experiencias históricas.

En el ejemplo soviético y las democracias populares, el cambio radical desmanteló todo el sistema. En el ejemplo chino, salvo la estructura política - en crisis en los sucesos de 1989-, se expendió el mercado y diversos tipos de propiedad privada extranjera y nacional, además de una afluencia masiva de capital extranjero.

\section{La movilidad social}

Alrededor de los años setenta, la U RSS era una sociedad en la cual, la gran masa de la población era completamente igual, y una gran proporción de ella

11. Ver la compilación e introducción de Vuskovic, Pedro; ACEITUno, Gerardo. «Teoría y política de la transformación social». Revista de la Facultad de E conomía, enero-junio de 1982, p. 21-24. M éxico: U N AM .12. M ichael Ellman. Se refiere a la U RSS, China y «las democracias populares». 0 p. cit., p. 211-218. Aunque también hace referencias a Cuba. 
estaba por debajo del nivel de pobreza. Existía una pequeña élite (alrededor de un $0,2 \%$ ). En comparación con 0 ccidente, la élite soviética era mucho menos poderosa en términos de riqueza y de independencia del Estado, y faltaba una gran clase media que desempeña un papel importante en 0 ccidente. «Las dos diferencias son un factor importante para explicar la fragilidad de los regímenes socialistas de Estado»12.

Para C hina, a pesar de que no existe dato estadístico sobre la distribución del ingreso (C hina no publica sus datos estadísticos al menos en esta época), las investigaciones sobre los estimados de ingreso constatan, según Ellman, una notable igualdad en la distribución del área rural, gracias a la reforma agraria. Tratándose de una población mayoritariamente agraria (al rededor de un 80\%) puede evaluarse como una tendencia global. Así, los efectos de las condiciones adversas son compartidos de manera más o menos equitativa y no hay una polarización de la riqueza en el campo.

Según estadísticas chinas, del período posterior a la reforma (1978), al inicio de ella se estimaban ciento veinte millones de personas por debajo de los niveles de pobreza, y una década después se reducían a cuarenta millones.

En 1975, D eng Tsiao-Ping, de las figuras históricas del Buró Político del Partido Comunista C hino, decía: «L os sueldos son bajos, y el nivel de vida no es alto. Tenemos solamente suficiente vestido y el estómago lleno. Con el fin desarrollar la economía, esta situación debe continuar aún durante un tiempo»13.

China, en los años setenta, también revelaba una estratificación social polarizada. Una gran masa uniforme en igual dad, una parte significativa por debajo de los niveles de pobreza y una reducida élite.

Las bases de las desigualdades, según el autor, se refieren a cuatro aspectos esenciales: la división social del trabajo, la familia, la división sexual de los roles y el papel del Estado. Con respecto a la primera, al gunos individuos son altos funcionarios y otros, trabajadores agrícolas, en la familia, los hijos de la familia de la intelligentia tienen las ventajas concomitantes en las sociedades sedentarias, o los descendientes de las élites, mientras que otros provienen de familias de obreros y campesinos.

En la división sexual de los roles, los puestos superiores están en manos de los hombres, mientras que muchos trabajos duros los llevan a cabo mujeres. Con respecto al papel del Estado, los que tienen altos puestos oficiales gozan de cargos atractivos y bien remunerados, no así los que son discriminados por razones religiosas, por razones de oposición política, u otro tipo de discriminación.

Ellman se está refiriendo a los polos, en cada uno de estos tipos de desigualdad de poder 0 de estatus. Sin embargo, estas desigual dades también culminan en una desigualdad de riqueza, aunque ello no esté asociado al ingreso monetario.

12. ELLM AN, M ichael. Se refiere a la URSS, China y «las democracias populares», O p. cit., p. 211-218. Aunque también hace referencias a Cuba.

13. Citado por ELLMAN, p. 219. 
Tabla 1. Grupos ocupacionales de élite en la U RSS en 1970a

Funcionarios del partido

Funcionarios del Estado, de los komsomols $y$ de los sindicatos

La intelligentiab

Los gerentes de las empresas (directores)

Los militares, la policíac,

el servicio diplomático

\begin{tabular}{cr} 
M iles & $\%$ \\
\hline 95 & 38 \\
60 & 24 \\
43 & 17 \\
22 & 9 \\
30 & 12 \\
250 & 100
\end{tabular}

Total

100

a Personas que ganan 450 rublos por mes o más y que tienen acceso a beneficios no monetarios sustanciales (el salario promedio en la U RSS era en 1970 de 122 rublos por mes).

b Los académicos (categoría superior de los profesores), los jefes de instituciones de educación superior, de los institutos, facultades y laboratorios, los jefes médicos, los altos funcionarios judiciales, los editores y periodistas superiores, los líderes en las artes y la burocracia superior artística.

c L L os oficiales de las fuerzas armadas y los órganos de seguridad del Estado.

Reproduzco, en la tabla 1, los resultados de una investigación sobre la élite en la URSS14.

Es decir, el 0,2\% de la población empleada tenía ingresos reales mucho más al tos que el promedio, porque existía una notable diferencia en los servicios médicos para la élite y para el resto de la población urbana, y aún peor para la población rural. I gual consideración se daba a la vivienda.

En China, desde 1956, la burocracia fue calificada según treinta rangos. El servicio médico fue gratuito para la élite, pero aún en 1979 no era completamente gratuito para la población. Además, en los grandes hospitales siempre había cuartos privados confortables para los cuadros del treceavo rango hacia arriba.

Estos ingresos no monetarios incluían lugares recreativos especiales, acceso a producciones de mayor calidad o extranjeras, un confort especial de equipamiento y habitacional, todos asociados a los cargos o rangos oficiales y al margen de los salarios. $\mathrm{N}$ o ha sido posible contar con más datos acerca de la proporción de ingresos que significaban estas asignaciones no monetarias, porque han constituido zonas silenciosas en las sociedades de socialismo de Estado. Recordemos el análisis de Trotsky con respecto a la U RSS de finales de los años treinta, en el sentido de que la burocracia estaba obligada sistemáticamente a encubrir sus privilegios, porque gobernaba en nombre de la igualdad de los trabajadores. Ellman por su parte cita otras investigaciones, que en el caso de China, durante la Revolución Cultural (1966-1976), los cuadros de Pekín castigados a trabajar y vivir en las aldeas, no sufrieron disminuciones

14. M ATTHEWS, M . (1975). «Top Incomes in the URSS: Towards a definition of the Soviet Elite». Survey, vol. 21, núm. 3. Citado por M. Ellman, p. 211. 
de su salario, pero tenían prohibido decir a las personas de la localidad cuanto recibían, así como la prohibición de hacer consumos suntuarios.

Sin embargo, ha existido una percepción social de este tipo de desigualdades que venimos comentando. A finales de la década de los años setenta, corría un chiste por la ciudad de M oscú: «¿Q ué diferencia había entre el socialismo y el comunismo?: La muralla del K remlin (hacia afuera era el socialismo, hacia adentro, el comunismo)».

En los primeros tiempos, después del triunfo de revoluciones políticas en estas experiencias, se produjo una vertiginosa movilidad social, que descrita en un gráfico podría representarse con una curva prácticamente vertical. La emigración masiva de propietarios, empresarios y de la intelligentia, exigió un reclutamiento rápido de personas, calificadas o no, para profesionalizarse en los puestos de dirección. Las nuevas metas de concentrar los recursos, organizar la economía y modernizarla de manera acelerada, también elevó y profesionalizó a miles de personas para crear el funcionariado necesario y movilizar la población hacia esos fines.

En estos momentos, además del liderazgo político que había encabezado esas tranformaciones o había sido el apoyo de las tropas soviéticas en la lucha de liberación contra el fascismo (en las democracias populares), las normas de asignación de personal fueron exclusivamente de índole política. La adhe sión al proyecto de cambio o la pertenencia al nuevo partido de gobierno fue el criterio central de asignación. N o quiere esto decir que cada rol de dirección con relevancia no contara con algún número de especialistas, sino que la asignación por mérito fue excepcional, y si no cumplía el requisito de adhesión era subordinado a una dirección superior que garantizaba el criterio de adhesión.

Aunque en el transcurso de las experiencias, la mayoría de ese funcionariado fue obligado a obtener un grado determinado de especialización o de profesionalismo ${ }^{15}$, en realidad el criterio de asignación de personal siguió privilegiando un criterio adscriptivo como el que hemos mencionado.

En la década de los años treinta en la U RSS se masificó la enseñanza técnica y se crearon numerosas universidades, con el objetivo de calificar masivamente la fuerza laboral, sobre todo la relacionada con la industria. En C hina, sin embargo, hasta antes de la R evolución Cultural las escuelas secundarias eran muy escasas, y sólo tenían acceso a ellas un reducido número de niños.

Aunque los ritmos de expansión de la enseñanza media y superior varió entre las experiencias, la masificación de la enseñanza hasta el nivel universitario fue un objetivo sustantivo de la política educacional.

Sin embargo, es necesario señalar que una vez lograda una cuantía de fuerza calificada, de acuerdo con los puestos de trabajo que la exigían, se redujo

15. Profesionalización indica que los puestos de dirección son ocupados por personas cuyo trabajo es dirigir y por ello perciben su salario. Profesionalismo, en cambio, indica que el puesto exige como condición o tendencia la terminación de estudios de nivel superior (universitarios). 
considerablemente la posibilidad de acceso a los centros universitarios y la reproducción de profesionales, se nutrió de los descendientes de la intelligentia y de otros grupos de élite. Por otra parte, se reprodujo la fuerza de trabajo menos calificada en los descendientes de obreros y campesinos. Éste es sólo uno de los aspectos que detiene la movilidad social ascendente en estas experiencias.

Si en los primeros momentos hay una estructura social abierta al ascenso una vez conformada la nueva élite, en su proceso de consolidación cristaliza una estratificación social que se nutre más en sentido horizontal y mucho menos en sentido vertical.

Al criterio de asignación personal debido a la adhesión política, se reúne la exigencia de un número de años de experiencia. Los rasgos observables de este fenómeno es lo que ha dado en llamarse la gerontocracia.

La adhesión política, como criterio de reclutamiento - explicable hasta cierto punto en los primeros momentos - tuvo una influencia negativa para los puestos exigentes de una especialización y de una capacidad instruida. En el transcurso del tiempo determinó la pérdida de prestigio del trabajo de alta calificación, por no encontrar su correlato en el estatus diferenciado, y porque otros trabajos rudos, de baja calificación, fueron premiados con ingresos mayores a partir de la escasez de fuerza laboral. La tendencia a recompensar puestos de media o baja calificación se verifica en todas las experiencias.

El tipo de asignación política y no de acuerdo al mérito, terminó por variar como tendencia las normas y los val ores en los diversos roles social es.

$\mathrm{H}$ emos analizado en el sistema económico, cómo la organización y la estructura jerárquica de dirección y control desde un centro, exigía un tipo de capacidad, que lejos estaba de incitar a la innovación tecnológica u organizacional, a las iniciativas hacia la reducción del despilfarro, a la imaginación para trascender las regulaciones burocráticas coyunturales, posiblemente perniciosas a más largo plazo, o simplemente sin sentido. La capacidad necesaria para mantener un rol directivo se reducía a cumplir las orientaciones de los organismos superiores y a evitar conflictos o tensiones entre los subordinados. Ambos aspectos conducían a la experiencia de «éxito social», aunque fuesen cumplidas de manera formal y aún en contra de la calidad de las finalidades definidas. Los aspectos válidos para el «éxito social » se trasladan hacia el resto de las actividades sociales, más allá del sistema económico. Se trata de manera en que el Estado decide, orienta y controla todas las esferas sociales.

M ientras más era necesaria una capacidad individual creadora y calificada en los diversos roles sociales, más se hizo evidente el freno a su desarrollo. Si la selección adscriptiva de acuerdo a la adhesión política, subordinó la selección del mérito y elevó a norma capacidades formales de ejecutar órdenes superiores y evitar conflictos sociales, la selección de acuerdo al criterio de edad - también adscriptivo- cristalizó el conservadurismo en la estratificación social. La renovación y competencia por puestos de mayor escala social aún bajo el primer criterio adscriptivo mencionado, se hizo inaccesible.

En realidad el proceso de socialización laboral en los socialismos de Estado ha tenido criterios de asignación de personal difusos y arbitrarios. Aún cuan- 
do en estas experiencias existía la llamada «política de cuadros» que pretendía regular de manera más o menos eficiente el ascenso social, éstas fueron parcialmente aplicadas o sencillamente irrespetadas.

Cuando expreso la existencia de una asignación de personal difusa y arbitraria me refiero a que no eran condiciones suficientes, la adhesión política, los años de experiencia e incluso una formación especializada para competir en condiciones equivalentes y ascender en la escala social.

El criterio de «años de experiencia» vino a estandarizar el tipo de «eficiencia» que hemos analizado. Es decir, el actor social, en los años de experiencia, adquiría las normas y los valores reales que conducian al éxito social. Eran normas de conservación, no de innovación.

N ikita Juschov, en el discurso central de XXII Congreso del PCUS (1961), señalaba que los «cuadros», a pesar de no ser eficientes en sus funciones, lejos de descender en la escala social, eran trasladados a puestos de similar nivel 0 a otros de mayor nivel de dirección. Esta realidad se conoció popularmente como el fenómeno de «corcho». U na vez que se entrara a formar parte de la élite, salvo errores graves de carácter político o errores interpretados en estos términos, el estatus adquirido tenía carácter vitalicio. Es por ello, la tendencia a reproducirse los diferentes estratos en un movimiento horizontal y no vertical.

El modelo produjo otras tensiones en los procesos de socialización y su relación con la movilidad social. M ientras la socialización laboral estandarizó criterios de asignación difusos y arbitrarios, y en el mejor caso, de acuerdo a criterios adscriptivos (adhesión política y años de experiencia), la socialización con respecto a la instrucción general y especializada estandarizó la selección de acuerdo al mérito. La competencia en cuanto a capacidades fue estimulada con recompensas de diversos tipos. Así, al actor social se le entrenó en normas y valores de acuerdo al logro para ascender en los diversos niveles de instrucción. Pero una vez finalizado este ámbito de socialización, entra en el proceso de socialización laboral, que cambia los criterios de asignación y establece el límite del ascenso social. Esto es un conflicto latente en el modelo.

La fragilidad de los socialismos de estado, que apunta Ellman, tiene relación con los problemas de la movilidad social que he analizado.

En primer lugar, la tendencia a la no alternancia de la élite y su dependencia de estatus, de acuerdo al cargo de dirección asignado por el Estado 0 el Partido. Esto favorece la cristalización del poder y su espíritu conservador. Como resultado, la polarización de la estratificación social y una reducida diferenciación de estatus 0 , en otras palabras, una concentración de estatus de mayor nivel en pequeños grupos. Así, la estructura social resultante muestra una élite reducida y una gran masa poblacional homogénea en estatus, como tendencia.

En segundo lugar, la ausencia de una clase media, que en otros sistemas sirve de barrera flexibilizadora de conflictos sociales, o de diversificación de los conflictos en la medida en que atenúa y «negocia» el enfrentamiento entre el Estado y la sociedad civil. Su ausencia en este modelo magnifica cualquier con- 
flicto por leve que sea en realidad, precisamente por la inexistencia de niveles mediadores. Es decir, la polarización de la estratificación social traduce el conflicto o desacuerdo de un sector social con respecto a un aspecto puntual, como un ataque frontal al régimen. Es en este sentido que se explica su vulnerabilidad, desde el punto de vista de la estructura social.

En los socialismos de Estado la diferenciación de roles, resultado de los procesos modernizadores, no se traduce en una diversificación de estatus. Precisamente la política consciente de igualdad social que se persigue, con la igualdad de ingresos por una parte y por la distribución de acuerdo a las necesidades en una serie de servicios por la otra, privilegia la homogeneidad social, pero impide la movilidad ascendente de forma sistemática.

Los límites a la movilidad social ascendente actúan contra los fines del desarrollo autosostenido. Se pretende una modernización y un nivel de desarrollo tomando los parámetros de los países más avanzados del capitalismo y se utilizan medios que pretenden romper con la racionalidad capitalista, al menos en la distribución de la riqueza social.

Sin embargo, a pesar de que estas sociedades fueron más igualitarias que cualquier sociedad capitalista - aunque hay excepciones- , estos límites de la movilidad ascendente y en la diferenciación de estatus actuó sistemáticamente en contra de los fines del desarrollo. El criterio de igualdad de recompensas a esfuerzos desiguales estimuló el menor esfuerzo, la inercia y la no innovación. No me refiero a casos aislados o a determinados sectores, sino a las normas institucionalizadas, con respecto a la asignación de personal y al sistema de recompensas.

En resumen, en el nivel del desarrollo de la estructura social, al igual que en el subsistema económico, el modelo se coloca en una encrucijada.

\section{El sistema político}

$\mathrm{N}$ o hay estudios sistemáticos sobre los sistemas políticos en las experiencias históricas de los socialismos de Estado, en el marxismo occidental. Sólo al gunos clasifican estos procesos como estados totalitarios o policíacosib.

N itos Poulantzas 17 intenta, de manera colateral a su estudio del Estado moderno, comparar los aspectos comunes del Estado occidental con los Estados del Este europeo. Según este autor los socialismos de Estado son Estados capitalistas modernos peculiares, autoritarios y con marcados rasgos totalitarios. Por ejemplo, cuando trata la ley en su funcionamiento social, interpreta en la acepción de «dictadura» de $M$ arx la dualidad de un régimen portador de la legalidad e ilegalidad en sí mismo. Es decir, la capacidad del Estado moderno (capitalista 0 «social ista») de crear una legislación que a la vez subordina a

16. Claudín, Fernando (1979). «Algunas reflexiones sobre la crisis del marxismo». La crisisdel marxismo. M éxico: U niversidad Autónoma de Puebla, p. 74.

17. PoulantZas, N itos (1979). Estado, poder y socialismo. Primera y cuarta parte. Siglo XX España. 
su poder y actúa por encima 0 al margen de ella siempre que obstaculice sus fines.

Lucio Colleti se detiene a analizar brevemente18 que los Estados del Este europeo, aún cuando presentan numerosas organizaciones sociales, éstas carecen de autonomía frente al Estado, rasgo según él evidente de la ausencia de sociedad civil en estos regímenes y de su cualidad totalitaria.

Se hace necesario explicar el término totalitario. El concepto surge a raíz de la guerra fría y es, en el lenguaje ideológico, una imagen que devalúa todo sistema que no presente los rasgos formales de la democracia representativa liberal. Sin embargo, el término se hace concepto en las ciencias políticas para designar regímenes políticos precisos. $\mathrm{H}$ ay autores que lo utilizan para enmarcar los fenómenos del fascismo y del estalinismo, y otros expenden el concepto a otros regímenes políticos de la posguerra.

Si bien hay numerosas clasificaciones de los regímenes autoritarios, éstos son totalitarios si cumplen, al menos, cinco rasgos esenciales.

a) La existencia del monopartidismo, o de varios partidos subordinados a un partido único. Éste se sobrepone a la organización del Estado, trastornando la autoridad y el comportamiento regular y previsible. Politiza los más diversos grupos y las más diversas actividades sociales, minando sus leal tades anteriores y los criterios de comportamiento, para subordinarlos a los principios y a los imperativos ideológicos.

b) La penetración total del cuerpo social con la destrucción de todas las líneas de distinción entre el aparato político y la sociedad. Es decir, la ausencia de autonomía de la sociedad civil frente al Estado-partido (aparatos).

c) La movilización política permanente, favorecida por la penetración estatal y política, hasta el nivel del individuo.

d) Una ideología que proporciona una explicación indiscutible del curso histórico, una crítica radical de la situación existente y una guía para su transformación igualmente radical. O rienta la acción hacia un fin sustancial, más que hacia instituciones o formas jurídicas. Justifica un movimiento continuo hacia el fin, y la destrucción o instrumentalización de cualquier institución y del ordenamiento jurídico.

e) El terror sistemático en el sentido de la violencia física sobre los cuerpos.

O bsérvese que incluso en los términos que se utilizan, existe un enfoque peyorativo del fenómeno. Es posible, sin embargo, visualizar bajo el lenguaje determinados rasgos y relaciones de poder de los regímenes de este tipo.

El aspecto del terror sistemático sobre los cuerpos es lo que hace pensar a varios autores en el concepto para explicar sólo los casos de la Alemania nazi, y la URSS de Stalin. M ás allá de este rasgo se descubren ordenamientos de jerarquía y control que han estado presentes en los socialismos de Estado. Reflexiono sobre algunas de las causas que influyeron en ese resultado. 
En la medida en que estos procesos históricos se plantearon un cambio estructural radical de la totalidad social y una ruptura con su pasado y a la vez con la lógica capitalista, asumieron la necesidad de crear una estructura capaz de garantizar, no sólo la organización y el funcionamiento social sobre nuevos pará metros, sino también trastocar las viejas normas, valores y conductas sociales hasta el nivel individual, en el entendido de fundar un nuevo tipo de civilización.

Esta finalidad suponía medios de dirección y control extraordinariamente centralizados y a la vez grados intensos de penetración social hasta el nivel de sus células primarias. Pretender crear una nueva civilización cualitativamente superior en países subdesarrollados que plantearon la meta esencial de modernizarse, es decir, civilizarse tomando como referente las sociedades más avanzadas del capitalismo occidental, resultó una finalidad en extremo contradictoria e inviable.

Sólo «civilizándose» se hacía posible una sociedad de bienestar generalizado, y ello se intentó por otros métodos. Sin embargo, una modernización acelerada y voluntaria sólo podría lograrse por medios despóticos desde las estructuras precapitalistas y rodeados de un sistema capitalista adverso. Estas condiciones hicieron priorizar la conservación del poder para realizar transformaciones de tal envergadura y una central ización rígida para enfrentar los riesgos externos y las metas internas.

El nuevo poder político se creó así, con una dualidad de enfrentamiento. $\mathrm{H}$ acia el exterior en un sentido defensivo, hacia el interior, no sólo erradicando los sectores desplazados del poder, sino también subordinando los intereses inmediatos de la población a los fines de la acumulación, la transformación de normas y valores y la preservación del poder.

La centralidad del poder político en la figura del Partido, se entiende en estas experiencias a partir de ser el agente, por excelencia, del cambio social. Por ello instrumentaliza el Estado y penetra la sociedad hasta un nivel individual politizando las estructuras y las conductas.

D e lo anterior se deduce la imposibilidad de desarrollar estructuras políticas de autogestión obrera o de democracia directa, aún cuando fuese un referente doctrinal.

En los socialismos de Estado, los valores y las normas de la empatía en los procesos de modernización hemos visto que son contrarios, no sólo hacia el afán de riqueza, sino a otro tipo de valores y normas que se ven limitados por los mecanismos sociales y por las finalidades ideológicas que persigue el proyecto. En estos procesos, la empatía posible era por lo tanto, con respecto a las élites internas, a la ideología socializada y a las normas y valores reales de la actuación de esas élites. Los resultados de este proceso de socialización política e ideológica los trataremos más adelante.

Los sistemas políticos de los socialismos de Estado han presentado marcados rasgos del régimen político definido como totalitario en el sentido del tipo de organización y del sistema jerárquico de decisiones.

Las características observables de esta tendencia son: La concentración del poder de decisión y de control en las máximas estructuras del partido. La subor- 
dinación y dependencia de las instituciones estatales, sociales y de la actividad y funcionamiento de toda la sociedad a ese nivel de decisión. La ausencia de autonomía de la sociedad civil frente al Estado y de éste frente al partido. Sistemas de control masivo en los procesos de socialización familiar, escolar, laboral, de residencia y de la opinión pública. Colateralmente, sociedades cerradas a la influencia de 0 ccidente, no sólo para evitar el efecto de demostración, sino también para lograr la «desconexión» a la cual se refiere Samin Amir. Es decir, romper con la lógica reproductiva del capitalismo.

En realidad, las experiencias de los socialismos de Estado han sido socie dades cerradas al flujo de intercambio de viajes hacia esos países o desde esos países hacia el exterior, también lo han sido con respecto al flujo de información pública de todo tipo y frecuentemente a los productos culturales occidentales. En otra medida, se «desconectaron» de manera temporal de la economía internacional, al crear una lógica reproductiva al margen del mercado mundial, sin embargo, desde los inicios de las experiencias, no dejó de importarse la tecnología de avanzada occidental.

Trotsky señaló cómo el trasplante de tecnología avanzada a un medio como el de la Rusia soviética, no podía generar análogos resultados a los de 0 ccidente. Se centró en dos condiciones que le hacían inviable. Por una parte, el subdesarrollo cultural - entendido en términos de conocimientos, capacidades y conductas entrenadas- por la herencia del pasado histórico. Por la otra, por los mecanismos de dominación política, que impedían la realización de un poder obrero a causa de la burocratización. Es necesario añadir a las observaciones de Trotsky el tipo de normas y valores que estandariza una estructuración social de este tipo, descritas en el presente trabajo en el subsistema económico y en la movilidad social. Los rasgos del sistema político, también apuntan a un resultado similar.

En qué medida estos sistemas políticos pueden considerarse modernos es lo que intentamos aclarar a continuación.

Si aplicamos los criterios de igualdad, capacidad y diferenciación, que aporta la variable de modernización política, estos regímenes son modernos. Sin embargo, variables tan generales no descubren las particularidades del sistema. Según los tipos de dominación descritos por Weber, los sistemas políticos de los socialismos de Estado presentan rasgos entremezclados de varios tipos ideales.

En los inicios de estas experiencias predominó un sistema de dominación basado en la autoridad carismática. Al menos así fue en la Yugoslavia de Tito, Lenin y Stalin en la URSS, M ao en China, Fidel Castro en Cuba, $\mathrm{H}$ o C hi $M$ inh en Vietnam y Kim II Sung en Corea del norte. En ese sentido se comportan como sistemas personalistas.

El carisma, es la cualidad de una personalidad, que se considera en posesión de dotes extraordinarias y no asequibles a cualquier otro. La pretensión de la legitimidad de la autoridad carismática se funda en la crencia de la autenticidad de la misión del caudillo, tanto por parte de éste como de sus seguidores. 
Es un tipo de autoridad que no se atiene a principios fijos de ordenamiento impersonal como en el caso de la autoridad racional legal, ni tampoco se atiene a principios sacros, observables en la autoridad tradicional. En su ruptura con el pasado, la autoridad carismática es revolucionaria, funda y crea nuevos valores y obligaciones. Es una autoridad cuya fuerza creativa e impetuosa se agita y disuelve las normas establecidas, sean tradicionales o racional-legales. La rutinización del carisma hace transformar las normas e instituciones en un sentido tradicional o legal.

La autoridad carismática puede ser hereditaria, pero sólo en el caso de C orea del norte - con acierto calificada por M ichael Lowy como «monarquía hereditaria»- se cumple este rasgo.

Con la rutinización del carisma, las normas o instituciones de los sistemas políticos adquieren otros rasgos, aún cuando la figura carismática influya sobre el ordenamiento burocrático que se cree. En el orden de la autoridad tradicional, las relaciones de los funcionarios administrativos y políticos con respecto a sus jefes en los núcleos más cercanos, se basan en vínculos de lealtad personal, prácticamente desde los niveles intermedios hasta el máximo nivel, por lo tanto en parte la asignación de cargos tiene la tendencia hacia este vínculo de carácter patrimonialista. En la experiencia de Cuba es marcada esta tendencia, y en el resto de las experiencias fue un criterio de asignación de los primeros años. Por otra parte, en el transcurso del proceso histórico, el liderazgo político adquiere el rasgo gerontocrático que se expande hacia el resto de la élite social.

La legitimidad de la gerontocracia descansa en la creencia de autenticidad en los valores y poderes de mando fundantes de la revolución política. Por lo tanto, la no al ternancia de las élites políticas se basa en este tipo de criterio de autoridad tradicional.

La organización burocrática tiene rasgos tradicionalistas en la medida en que las prerrogativas y remuneraciones en especie del funcionariado élite se decide por el liderazgo político y no está sometido a ninguna norma jurídica o escrita pública. Con el tiempo se estandariza relativamente una asignación de deberes y recompensa en la relación cargo-estatus.

En resumen, los rasgos de la autoridad tradicional, presentes en los sistemas políticos de los social ismos de Estado, se encuentran en las normas y valores que conforman la élite política y en parte en las normas y valores de la organización burocrática. Rasgos de la gerontocracia y de patrimonialismo se encuentran en la asignación de personal y en el sistema de deberes y recompensas.

También estos sistemas tienen rasgos de la autoridad legal-racional. C rean jerarquías fijas de subordinación en todos los niveles políticos y estatales. La organización burocrática perfila con el tiempo el ámbito de competencia de cada uno de los funcionarios de manera estricta, los funcionarios reciben sueldos fijos, no son elegidos, son nombrados por una autoridad superior. Estos sistemas no han sido meritocracias y en ese sentido no cumplen con los ras gos de la autoridad legal-racional.

A saber: la incorporación de funcionarios se basa en la demostración de competencia especializada por medio de exámenes competitivos, o de la pose- 
sión de grados o diplomas que testifiquen las cualificaciones apropiadas. Éste no ha sido el criterio de asignación de personal o lo ha sido de manera muy débil. El funcionariado se designa a partir de sus cualidades técnicas. No ha sido el criterio central de asignación. Existe una separación entre el funcionario y su cargo, de modo que éste no es bajo ninguna condición propiedad exclusiva del titular. D e manera formal, este rasgo se cumple en los regímenes del socialismo de Estado. Sin embargo, la dependencia del funcionario del cargo para recibir determinadas recompensas - sólo asequible por el cargo que ocupa- determinó una dependencia personal al cargo más acusada que en los regímenes capitalistas, precisamente porque el estatus está relacionado a este tipo de rol social y no es posible lograrlo, o excepcional mente está logrado por los que desarrollan otros roles sociales.

Los sistemas políticos de los socialismos de Estado han sido parcialmente modernos y, en igual sentido, tradicionalistas. La conclusión no permite aún develar la lógica interna de su funcionamiento y las implicaciones de su legalidad con relación a una racionalidad instrumental y con respecto a las condiciones para la acción del actor social.

El problema central de los subsistemas políticos del modelo ha sido la ausencia de factores de equilibrio del poder. La eliminación de la separación entre los aparatos ejecutivos, legislativos y judiciales es sólo un aspecto del problema. N o me refiero a una separación de funciones que existe en el modelo, se trata de la ausencia de relativa autonomía de estos poderes, que implica niveles de dirección social no sujetos a al gún control público.

Por otra parte, es de remarcar la ausencia de relativa autonomía de las organizaciones sociales con respecto al liderazgo político y estatal, en relación con la definición de sus intereses y también en la asignación de sus direcciones, prerrogativas y organización. Esto inhibe una participación activa en la evaluación y decisión de las políticas por parte de los diversos grupos sociales, que los convierte en receptores y ejecutores de políticas sobre las cuales no tienen influencia. El control de los medios de difusión masiva y la ausencia de relativa independencia del poder central también produce una débil opinión pública.

En el discurso político y en la literatura de ciencias sociales de esas experiencias se planteaba la existencia de equilibrio entre los elementos del sistema político, sobre todo en el interior de los elementos que componían el sistema. Así el Congreso del Partido era la máxima dirección colegiada de la organización al cual se subordinaba el C omité C entral del Partido y a este órgano rendía cuentas el Buró Político, que entre las reuniones del Comité Central era el encargado de dirigir la política acordada por el Congreso.

En realidad, la toma de decisiones era a la inversa. En una estructura piramidal, la decisión entre las políticas partía de los buroes del partido, de ahí se orientaban al Comité Central y luego a los congresos. Continuando la estructura piramidal desde el Comité Central a los buroes regionales, provinciales, locales, hasta un nivel de fábrica, empresa, o esfera de servicio.

Con el Estado ocurría un proceso similar. El órgano legislativo controlaba al ejecutivo, al delegar sus funciones entre sesión y sesión del Parlamento. Del 
Parlamento se orientaba hacia las direcciones administrativas regionales, provinciales, local es. También en este esquema, la máxima decisión recayó en realidad en el ejecutivo y los parlamentos tuvieron poca influencia, por no decir ninguna influencia en la política acordada.

El problema se complicaba, aún más, por la dualidad de funciones de máximo nivel estatales y partidarias en un mismo reducido grupo de personas. Rolan M ousnier, clasifica este tipo de sistema jerárquico - en el caso de la URSS- como una sociedad filosófica estatal. En el sistema, la élite burocrática y política se reproduce por procesos de cooptación, herencia y endogamia19. Es el proceso de reproducción horizontal que señalamos en el análisis de la movilidad social.

M ás allá de revelar la incongruencia de un sistema de este tipo con lo que desde $M$ arx y Lenin se entendía debía ser un poder obrero - aspecto extensamente abordado en la literatura marxista- , es necesario aún determinar hasta qué punto fue funcional el sistema a si mismo.

La concentración del poder de decisión, evaluación y control de la actividad social debilitó extraordinariamente al sistema. Por una parte, erosionó en el transcurso del tiempo sus bases sociales y, por otra parte, inhibió la posibilidad de impedir políticas erráticas, a mediano y largo plazo. La lentitud y distorsión en la percepción de los problemas sociales y los cambios de política, atestiguan los obstáculos burocráticos para informarse de la realidad social. Existió también una percepción generalizada del carácter improvisado de las políticas. A pesar de la existencia de planes exhaustivos anuales, quinquenales y de varias décadas, éstos en realidad eran sistemáticamente alterados, revisados u olvidados.

La improvisación política (método de ensayo-error), la falta de participación social activa y la ausencia de retroalimentación adecuada del sistema político con respecto al resultado de su gestión, acumuló tensiones sociales y el evó los costos políticos y sociales posiblemente regulables a tiempo con otro tipo de gestión. En este sentido, el sistema se hizo ineficiente a sí mismo, aunque sus síntomas de deterioro sólo se hicieran observables en tiempo de crisis aguda o derrumbe del sistema. D esde un criterio de racionalidad instrumental el sistema acumulaba obstáculos a su funcionamiento.

Este tipo de sistema político, cuyas características generales hemos reseñado, trazó pautas de conducta al actor social.

Es criterio de la autora del presente trabajo, que un sistema político estructurado de la manera descrita, genera normas institucionalizadas para la acción social que presenta rasgos de disolución y desintegración social. Específicamente el tipo de anemia que produce la «sociedad de masas».

Tironi recoge tres definiciones de la «sociedad de masas» y asume en su análisis la que nos parece útil en el contexto de nuestro tema20.

19. Ver Las jerarquías sociales (1970). Buenos Aires: Amorrurtu, p. 130-140.

20. TIRONI, Eugenio (1990). Autoritarismo, modernización y marginalidad. Santiago de Chile: Ediciones SU R, p. 79-109. 
La sociedad de masas se caracteriza porque en ella la población conforma un agregado de individuos relacionados entre sí, no a través de una variedad de grupos independientes, sino por su relación directa con una autoridad común, particularmente el Estado. La sociedad de masas se distingue, de este modo, por la atomización de los individuos y por la ausencia o debilidad de las asociaciones intermedias capaces de garantizar la autonomía de los individuos frente al Estado [... ] se caracteriza - además por la presencia de un Estado fuerte que centraliza las comunicaciones y decisiones concernientes a la sociedad- que van más allá de los diferentes grupos primarios. Esto mismo tiende a politizar las demandas de los grupos sociales, pues cualquier eventual participación de la población en la sociedad gl obal, ha de pasar por el Estado21.

Los resultados de un ordenamiento de este tipo conduce a la apatía y/o al activismo, éste último a partir de la búsqueda de una identidad externa en un líder, en la imagen colectiva del movimiento o el partido. El problema de esta segunda variante es que hace la comunidad social extraordinariamente vulnerable al influjo de ideologías extremas, frente al desajuste entre las condiciones de vida material, las instituciones sociales y las representaciones colectivas.

En los sectores en que genera apatía, la persistencia de una situación frustrante lleva a conductas de conformidad y resignación. El conformismo es la resistencia a entrar en desacuerdo frente a la autoridad o al grupo, o como miedo al comportamiento desviado, por aversión a las consecuencias, o por la pérdida de beneficios que acarrearía el desacuerdo22.

La resignación es la conformación patológica a una situación intolerable. Independientemente de los efectos de deterioro de la autoestima en el actor social, las implicaciones sociales son una incomprensión de la causalidad en este Estado.

Por una parte, puede ser entendida como la incapacidad personal de alcanzar el progreso personal, ésta sería la causalidad interna y, por otra, la causalidad externa, que situaría los acontecimientos de la vida supeditados a fuerzas superiores fuera de control y frente a las cuales sólo cabe ren dirse.

Tironi señala que una situación de disolución social no conduce a la formación de movimientos sociales. Por el contrario, si llega a un límite para expresar algún tipo de violencia ésta se produce como "conductas de crisis», es decir, revueltas puntuales carentes de contraproyecto al statu quo. En las condiciones de disolución social son las élites del Estado o del partido las que tienen la iniciativa social.

Si me refiero a los síntomas de disolución social, es porque considero que en el modelo de socialismo de Estado que dominó este siglo, después de los

22. Tironi señala que el conformismo no significa que las personas no perciban otras alternativas de conducta, sino más bien que, por distintas razones, prefieren no emitirlas. El conformismo no es necesariamente congruente con el sistema de creencias y valores que el actor social posee de forma individual. 
primeros años de efervescencia revolucionaria cuando las relaciones sociales se hicieron más intensas y la posibilidad de integración social se hizo evidente (para la mayoría), comienza un proceso de disolución de estos vínculos solidarios intensos y un proceso indetenido de atomización social y desintegración.

Los rasgos de activismo «externo» y/o apatía, son el resultado de normas estandarizadas en el subsistema económico en la movilidad social y en el tipo de ordenamiento político. Los riesgos son notables y se hicieron evidentes en el derrumbe del «socialismo real» y en la reestructuración económica de China a un «socialismo» de mercado o de Vietnam en un mismo sentido.

El activismo «externo» muestra su vulnerabilidad en los virajes de política interna. La ausencia de identidad del actor social en estructuras organizativas intermedias que expresen sus intereses peculiares, le hace depender del curso de la política global. C ada viraje de política exige del actor social una adhesión, cada vez menos racional, y una conducta cada vez más sacra frente a la dirección social, lo cual erosiona paulatinamente las posibilidades de desarrollar un «sujeto» consciente coordinador de sus capacidades y opciones, y condiciona conductas cínicas y apáticas.

Tironi señala: «U na sociedad carente de grupos secundarios, de asociaciones intermediarias o corporaciones, en los hechos del ega unidad a la institución estatal, a la vez que queda inerme ante ella [... ], la lógica de la acción estatal estará dirigida a ganar mayor centralidad y autonomía, profundizando la atomización de la sociedad $\gg 23$.

$\mathrm{H}$ asta qué punto «vació» las relaciones sociales, políticas como el «G ran Salto», «La Revolución Cultural», la colectivización forzosa, el desmantelamiento del gobierno de Stalin, Ios hechos de H ungría, C hecosl ovaquia y Polonia, por citar al gunos, es un fenómeno que sólo recogió la literatura parcialmente y no fue objeto de análisis de las ciencias social es en estos países, 0 no pudo serlo, por la situación de «fortaleza sitiada» que asumió el «socialismo» en estas experiencias.

La ausencia de estudios sociológicos concretos con respecto a las expectativas, normas y valores reales de los actores sociales en los socialismos de Estado impidió detectar hasta qué punto las sociedades de este tipo estaban en los límites de la crisis. Por ello fue en extremo asombroso para muchos la facilidad con que se destruyeron estos procesos con el Ilamado «efecto de dominó». Sería muy superficial encontrar la causalidad de la rapidez de los acontecimientos o de las reformas chinas y vietnamitas en el resultado de la labor de inteligencia militar occidental o en la traición de una u otra personalidad o élite de poder. Algunos de estos factores y otros develaron una «densidad dinámica» endeble y una profunda atomización social, con los rasgos de ruptura y disolución de la relación individuo-sociedad que hemos reseñado. 


\section{La ideología}

El esquema de análisis de Goran Therborn ${ }^{24}$ nos parece fructífero para desglosar el modo en que opera la ideología en una sociedad compleja moderna. El autor se distancia de la acepción de ideología como conciencia falsa, porque el acceso a una conciencia verdadera, por ejemplo en la clase obrera, sería posible a partir de su «nterés» de clase. Esta reflexión es para Therborn un residuo utilitarista en $M$ arx, que es necesario desechar.

Sin embargo, entender la ideología como un proceso social, de interpelación al individuo, o la forma mediante la cual los actores sociales viven conscientemente en un mundo que comprenden en diversos grados y modos, incluye también un conocimiento errado, o falso, en contraposición al conocimiento verdadero en la medida en que el acceso al conocimiento de la totalidad social es fragmentado, y además porque el acceso a la información está mediado por las jerarquías sociales en una sociedad concreta.

Therborn señala como condición indispensable para el desarrollo de una actuación consciente del sujeto, el grado de conocimiento o ignorancia con respecto a los mecanismos y ordenamientos sociales (explícitos u ocultos a una percepción del sentido común) que constituyen el contexto de la acción social. Este conocimiento es dado en los procesos de socialización escolar, política, laboral, familiar, ámbitos en los cuales compiten diversas ideologías, en un concierto «cacofónico» según la imagen que nos ofrece el autor que venimos comentando.

Sin embargo, en el modelo objeto de análisis, ya hemos dejado explícito que por las condiciones en que se desarrolla y por los fines que persigue, esta «cacofonía» es débil si la comparamos con una sociedad capitalista actual.

El hecho de que los procesos históricos de transición al «socialismo» se hayan construido en un contexto internacional adverso, y los fines de crear una nueva civilización, en el sentido de relaciones sociales y val ores culturales diferentes a los dominantes en el resto de los países no «social istas», resultó en un ordenamiento social muy centralizado y controlado desde las máximas direcciones sociales, un cierre de estas sociedades hacia el exterior y un peso de la ideología superior al que presenta el capitalismo.

La significación de la ideología 25 en los socialismos de Estado alcanzó la interpretación o contrastación de toda conducta social con el discurso ideológico y político dominantes o a la inversa, este discurso intentó prescribir las conductas sociales del sujeto en todos los escenarios de la interacción social, desde los valores morales en las relaciones interpersonales hasta los valores de adhesión al sistema social y a la doctrina marxista-leninista dominante.

24. Ver La ideología del poder y el poder de la ideología (1987). M adrid: Siglo XXI.

25. Asumo el concepto de ideología como lo explica Goran Therborn. El concepto incluye las nociones de «experiencias» cotidianas como las elaboradas doctrinas intel ectuales, tanto la «conciencia» de los actores social es como los sistemas de pensamiento y los discursos institucionalizados de una sociedad dada. 0 p. cit., p. 2. 
En igual sentido prescribió lo que podría entenderse por una conducta socialista y lo que se desviaba de este paradigma26.

D esarrollar un proceso de socialización ideológica tan intenso, masivo y de penetración hasta las células básicas de la sociedad perfiló muchos de los contornos del discurso ideológico.

En este acápite utilizo el término sujeto en la doble acción que supone todo proceso de interpelación ideológica. Por una parte, la interpelación persigue la sujeción o sometimiento y, por la otra, la cualificación del actor para su funcionamiento en la sociedad y su resistencia.

M i reflexión apunta a encontrar las múltiples causalidades posibles para que se produjese, lejos de una conciencia en ascenso de clase, un «vaciamiento» ideológico masivo que no permitió contrarrestar las rupturas de los sistemas políticos en el «socialismo real» europeo. El hecho de que otras experiencias no hayan develado similares síntomas es, a mi modo de ver, sólo el resultado de la ausencia de una fractura del poder. Pero si ésta ocurriese, presentaría rasgos similares de emergencia de una sociedad civil cuyos perfiles ideológicos cal ificaríamos de heterogéneos, ingenuos, primitivos y regresivos. Al menos esa es la percepción de esta autora al observar lo que Gunder Frank y otros autores llaman «las revoluciones de 1989».

Es criterio también de esta autora que un «vaciamiento» ideológico en los términos en que voy a explicar, no ocurre de golpe, en un breve tiempo, sino que es el resultado de un largo proceso social en el que son determinantes la teoría o el discurso ideológico, los procesos de socialización del actor social y, por lo tanto, la contrastación en esa interacción con la realidad fáctica.

Comencemos por la teoría y el discurso ideológico político. En las experiencias, la teoría y el discurso ideopolítico presentaron una fusión que hace imposible deslindarlos. Para todos es conocido que la variante marxista que se erigió en política e ideología oficial fue el marxismo-leninismo soviético. Esta corriente se formó en los años treinta en la URSS y se expendió a todas las experiencias históricas de socialismo. La variante maoísta o la de Kim II Sung con pequeñas variaciones funcionó de igual manera en la sociedad que la variante soviética. Para su difusión masiva se crearon los manuales de triste recordación. En la única experiencia en la cual se ofreció resistencia a la enseñanza del marxismo por manuales con la variante dogmática fue en Cuba. Es conocida la polémica de Aurelio Alonso y H umberto Pérez sobre la utilización de los textos clásicos o los manuales para la enseñanza del marxismo. Infortunadamente venció la visión de los manuales defendida en la discusión

26. Es ilustrativo el peso ideológico en el modelo, la postura que tuvo las direcciones políticas con respecto a la creación artística. La imposición del «real ismo socialista» en todo el socialismo de Estado europeo, la Revolución Cultural en C hina, las declaraciones de Tito acerca del arte moderno como una corriente ideológica adversa al socialismo, o en el caso de Cuba, la década de los setenta, señalada por los críticos de artes plásticas cubanos como la «década gris». Todos esos procesos demuestran que la creación artística fue eval uada en términos rígidamente ideológicos y acotada de manera formal y simplificadora. 
por H umberto Pérez, aunque no fuese el único, por supuesto, defensor de esta línea.

La variante ortodoxa dogmática que se impuso presentó los siguientes rasgos:

1. Una posición frente a los textos clásicos de M arx, Engels y Lenin, sacra, es decir, una lectura religiosa, en la cual se pretendía encontrar respuesta a todos los problemas del mundo contemporáneo.

2. Paradójicamente, extraer citas fuera de contexto para validar situaciones totalmente diferentes a las originales.

3. La vulgarización y simplificación de las tesis marxistas, en el entendido de hacerlas accesibles a los sectores populares.

4. La censura y prohibición, el silencio sobre marxistas soviéticos y occidentales que criticaran la experiencia soviética o no coincidieran con la apreciación que tenía el gobierno soviético sobre el mundo contemporáneo.

5. Una postura maniquea en la interpretación de los fenómenos internos e internacionales. H acia adentro la teoría y el discurso se dedicaba a embellecer la realidad social, sin conflictos y a validar cada decisión política. La interpretación con respecto al capitalismo internacional era la de su inminente derrumbe, descomposición y depauperación progresiva.

Considero el aspecto más trágico o grave de estos rasgos de la teoría y del discurso, la prohibición o silenciamiento de las diversas corrientes marxistas que se desarrollaban fuera de los países socialistas. Por otra parte, la prohibición de toda literatura de ciencias sociales occidental, lo cual condujo a un empobrecimiento intelectual en países que expendieron la instrucción general masiva. El acceso a esta literatura occidental (marxista y no marxista) requería de un permiso especial otorgado a quienes se les daba la tarea de «criticar» el «revisionismo» 0 el carácter «burgués reaccionario» de esos autores. Los textos producidos a este fin dan cuenta del espíritu de mediocridad que se imponía al ámbito intel ectual de las ciencias sociales en estas experiencias. La desinformación, manipulación, maniqueísmo, simplificación y distorsión son sus rasgos más definitorios.

Unido a la desinformación, a las ciencias sociales de estos países se les prohibió estudios evaluativos de la realidad social que plantearan problemas y alternativas de solución diferentes a las comúnmente aceptadas por las direcciones políticas.

La desinformación, la censura a evaluaciones criticas, y un discurso monocorde se impuso por medios coactivos de diversa índole, no sólo al desarrollo de las ciencias sociales, sino también a los restantes aparatos ideológicos²7.

27. D efino como aparatos ideológicos, los escenarios donde se concentra el discurso y las prácticas no discursivas afines, también los lugares de conflicto ideológico: medios de difusión masiva, el sistema de enseñanza en su conjunto, familia, barrios, centros laborales. D entro del Estado los órganos judiciales. Ver Therborn, Goran. O p. cit., p. 70. 
H emos reflexionado sobre los costos que desde una racionalidad instrumental del poder produjo la ausencia de una autonomía relativa de las diversas instituciones políticas y de los diversos grupos sociales organizados. En el ámbito de las ideas, si en los primeros tiempos todas las experiencias mostraron flexibilidad para la polémica y la discusión de variantes al ternativas, en la medida en que se consolidó el poder y pasó la efervescencia revolucionaria inicial, se clausuró la posi bilidad de la discusión interna y de evaluaciones alternativas frente a cada asunto social, a partir de entonces interpretado en términos de vulnerabilidad a la «unidad» política e ideológica del sistema.

En el modelo no existen contraaparatos ideológicos, por lo tanto el proceso de interpelación ideológica que somete y cualifica al actor social, le entrena para ser funcional al sistema pero no para desarrollar una capacidad de resistencia. Esta capacidad de resistencia a la dominación no es otro proceso que el necesario para contrastar, «negociar» y participar activamente de manera socialmente organizada en la definición de los conflictos, la lógica y las alternativas posibles del orden social dado. Es el pilar fundamental para internal izar las normas y los valores comunes a la sociedad, así como aquéllas que representan las necesidades social es particulares de los agentes sociales.

En otras palabras, no es posible el desarrollo de un actor social consciente si no logra una autonomía relativa del discurso dominante para expresar la adhesión o distancia, o ambos a la vez, de una forma organizada y pública. 0 tro tipo de adhesión exige una aceptación inevitable del discurso ideológico, en la cual se exige del actor social una posición inerme y afirmativa.

Lo anterior no significa que miles y millones de personas en los países «socialistas» no hayan intentado una resistencia a este ordenamiento ideológico monocorde, de lo que se trata es que todos los que lo intentaron sufrieron la excomunión ideológica y política respaldada por sanciones no discursivas de distinto grado.

Toda ideología se pronuncia sobre lo que existe, lo que es bueno y lo que es posible, así como sus contrarios, lo que no existe, lo que es injusto, incorrecto y lo que no es posible. En el caso que analizamos el discurso iluminaba zonas de la realidad y ocultaba otras - como cualquier discurso político ideológico- . En relación con la historia, discurso y teoría expresaban los hechos que podían tener una lectura de un proceso único y continuo, sin fracturas. También hacía el recuento de los éxitos globales y ocultaba los fracasos y las políticas erráticas, o sus costos. Un sentido progresivo e irreversible del sistema y de la historia que culminaría en un futuro casi paradisíaco. Sin faltar una discusión real o abstracta con los «enemigos» del sistema.

El lector puede considerar que los rasgos anteriores están presentes en cualquier discurso político o que, en definitiva, ésas son las reglas del discurso político. Cada ideología tiene un cuerpo defensivo, por ejemplo el hecho de exaltar

28. Para encontrar los rasgos comunes en la teatralización del discurso y de los rituales recreadores del patrimonio histórico en las prácticas del poder político, véase N éstor GARcía Can CLIN I. Culturashíbridas. De. cit., p. 151-158. 
parcialmente la realidad y no pronunciarse sobre otros aspectos. También la constatación de aspectos indeseables en la realidad, pero la justificación en tal caso de su existencia inevitable, etc. En la manera de funcionar, el discurso político «socialista» no se distanció en nada del tradicional discurso político burgués.

La mayoría de los autores marxistas enjuician, desde el punto de vista ético, la utilización del marxismo para una práctica política de dominación, precisamente porque desde su concepción inicial ha sido la única teoría social que se creó para revolucionar radicalmente las estructuras tradicionales de dominación social. D esde su razón de ser tiene sentido enjuiciar éticamente los destinos de la teoría que cumplió una función inversa a los fines para los cuales fue creada. N o es mi intención desarrollar esta crítica, sino apuntar su existencia y singularidad.

0 tros procesos hubieran compensado esta manera tradicional de construir el discurso político-ideológico. La capacidad evaluativa relativamente autónoma de las ciencias sociales hubiera podido detectar a tiempo muchos de los problemas acumulados o no evidentes para la dirección social y ayudar en las propuestas de solución.

En segundo lugar, una práctica social organizada relativamente autónoma permitiría lograr dos fines. La contrarrespuesta a esos modos tradicionales de construir el discurso y, en ese proceso, la internalización de normas y valores que permitieran una concienciación creciente de los actores sociales. Ambos procesos no son contrarios al sistema. Permiten eficacia instrumental de la ideología y la transformación ideológica del actor social de acuerdo a los fines de convertirle en un sujeto social. Por supuesto, eso significa una mayor complejidad en los procesos de dirección social difícilmente realizable después de años de inercia, simplificación y autoritarismo en la comprensión del trabajo ideológico.

André G orz 29 plantea la cautela que debían tener los dirigentes soviéticos después del XX Congreso del PC US en 1956, para democratizar las estructuras políticas y económicas. Sus razones apuntaban a que un proceso rápido derrumbaría el sistema porque el actor social no estaba preparado, entrenado para participar democráticamente en la sociedad. Treinta años después se hizo la perestroika y sus detractores hubieran planteado las razones de G orz en 1959. El problema es que el modelo es incapaz de entrenar democráticamente al actor social, porque su manera de ordenar y estructurar la dirección social reproduce la cristalización del poder.

La matriz material de las ideologías se encuentra en un sistema estructurado de afirmaciones y sanciones 30 . Si el sistema de afirmaciones es extraordinariamente reducido en sus márgenes de aceptación de la diversidad, las posibilidades de adhesión, o de conductas afirmativas se erosiona numéricamente en el tiempo. Esto es un proceso que el actor social constata en los procesos de socialización.

29. Gorz, André (1964). H istoria y enjenación. M éxico: Fondo de Cultura Económica,

p. 214-235 (edición original, 1959).

30. Therborn, Goran. O p. cit., p. 28-30. 
Tabla 2. M ecanismos de sometimiento por su efecto de dominación ideológica

\begin{tabular}{lll}
\hline & \multicolumn{2}{l}{ Régimen alternativo posible } \\
\cline { 2 - 3 } Modo de interpelación & Sí & N O \\
\hline Lo que es & Adaptación & Sentido de la inevitabilidad \\
Lo que es bueno & Sentido de la representación & $\begin{array}{c}\text { Diferencia } \\
\text { Resignación }\end{array}$ \\
\hline o que es posible & M iedo & Resign
\end{tabular}

El otro componente de la materialidad de las ideologías es precisamente la contrastación del contenido del discurso con su correlato en la práctica. El actor social es sometido a reglas de conducta que no tienen relación directa con el discurso. Las aprende por el método de ensayo-error en su actividad social práctica cotidiana.

El desfase entre el discurso y la práctica es consustancial a cualquier funcionamiento ideológico, precisamente por las maneras en que se construye el discurso. En el caso de las experiencias objeto de análisis, la polarización entre discurso y práctica es más evidente por la centralidad de un discurso ideológico único y totalizante que no compite con otras ideologías en confrontación pública, porque no son reconocidas en su existencia o porque las evaluaciones ad hoc de este desfase no se social izan 31 .

Reproduzco la tipología de Therborn sobre las formas de dominación ideológicas aplicadas por el autor a las sociedades capitalistas modernas, pero que tiene valor analítico para el modelo (tabla 2).

El autor no tiene una tipología similar para estudiar analíticamente las formas de contrarrespuestas ideológica a los procesos de sometimiento-cualificación. En este sentido se estudia la dominación en una sola dirección.

La adaptación es el proceso mediante el cual el sujeto se aísla de los problemas políticos y sociales, dedicando su esfuerzo a reproducir sus condiciones de vida en el trabajo, ocio, familia, etc., porque las considera más importantes para su existencia.

El sentido de la representación existe cuando los actores sociales se sienten representados en la política de los dominadores, aunque se exprese en sincronía esa relación. El miedo no sólo se expresa en relación también las consecuencias materiales, con la desobediencia, sino también a lo incierto de un cambio.

El sentido de la inevitabilidad se refiere a la obediencia por ignorancia de cualquier tipo de alternativa. Es el resultado de la marginación política que conlleva un al ejamiento del sistema político.

La diferencia es la apreciación sobre los dominadores en los que éstos son concebidos como un grupo poseedor de cualidades superiores de cualificaciones necesarias para dominar y que sólo ellos poseen.

31. No dudo de la existencia de estudios ad hoc de este tipo, realizadas por aparatos especiales del partido o de la seguridad, pero no han sido materiales que se hayan publicado. Al menos la autora no conoce ningún estudio de este tipo en los ex-países «socialistas». 
La resignación es la obediencia que se deriva de la percepción en la imposibilidad práctica de una alternativa mejor.

En las alternativas positivas o afirmativas observamos que sólo el sentido de la representación manifiesta una adhesión consciente. Las restantes son adhesiones indirectas o pseudoadhesiones.

En las alternativas negativas el sometimiento también se acata, pero son todos factores de disolución ideológica con respecto a los fines políticos e ideológicos de adhesión consciente.

El sistema de cualificación sin contraaparatos ideológicos y sin autonomía relativa en organización y del discurso ideológico de contrarrespuesta, condiciona una conducta ideológica, aunque sometida, contraria en valores y normas a la formación de un sujeto consciente, activo, coordinador de sus opciones y creador de alternativas. Es en este sentido que hablamos de un «vaciamiento» ideológico en relación con los valores de solidaridad, altruismo, honestidad, creatividad e iniciativa que en discurso y teoría se elevó a conductas paradigmáticas del ideal socialista.

La descripción y el análisis del modelo nos conduce a tres conclusiones apreciables.

Si el proyecto de transformaciones se planteó el desarrollo, en el sentido modernizador tradicional, los medios seleccionados lograron un desarrollo inicial, el estancamiento y luego la necesidad de reestructurar esos medios para hacerles real mente congruentes con el fin modernizador.

Plantearse el objetivo del desarrollo y a la vez la superación de la racionalidad capitalista, demostró ser inviable. No existió una subversión de la realidad capitalista en sentido neto, aún cuando la lógica funcional del sistema se distanciase durante al gún tiempo de la lógica capitalista. Este distanciamiento fue macrosocial, pero reprodujo en los actores sociales condiciones similares 0 aún más restrictivas para la actividad social, aunque los beneficios infraestructurales y de servicios mejoraran en sentido considerable con respecto al punto de partida de esos procesos.

La expansión de nuevos valores y normas conoció movimientos de avance y retroceso, pero la tendencia condicionada por los mecanismos del modelo, termina por imponer efectos de desintegración social evidentes en un desplazamiento de la actividad social hacia los grupos primarios - la familia, por ejemplo- , un distanciamiento de los asuntos sociales y el retroceso hacia el espacio de la vida privada, la tendencia hacia un imaginario social «fatalista» y la desarticulación política e ideológica cuyos rasgos recorren un amplio espectro de conductas. D esde la apatía y la resignación hasta la violencia extrema - con actos espontáneos y puntuales - 0 la adhesión a ideologías extremas y el fanatismo.

Los síntomas revelan que la desarticulación ideológica significa que el actor social cambia su percepción en relación con su sentido de pertenencia, con el lugar de su existencia y con las posibilidades de alternativas a la realidad presente. Por eso afloran otras ideologías latentes, que el proceso de transformaciones sociales no logró más que silenciar por algún tiempo. 